\title{
Pregnancy-associated lung cancer: a clinical and scientific challenge more than treatment dilemma
}

\author{
Weitao Zhuang ${ }^{1,2} \wedge$, Guibin $^{\text {Qiao }}{ }^{1 \wedge}$ \\ ${ }^{1}$ Department of Thoracic Surgery, Guangdong Provincial People's Hospital, Guangdong Academy of Medical Sciences, Guangzhou, China; ${ }^{2}$ Shantou \\ University Medical College, Shantou, China \\ Correspondence to: Guibin Qiao, MD, PhD. Department of Thoracic Surgery, Guangdong Provincial People's Hospital, Guangdong Academy of \\ Medical Sciences, 106 Zhongshan Second Road, Guangzhou 510080, China. Email: guibinqiao@126.com. \\ Comment on: Yang L, He YT, Kang J, et al. Clinical features and intervention timing in patients with pregnancy-associated non-small-cell lung cancer. \\ J Thorac Dis 2021;13:4125-36.
}

Submitted Jul 25, 2021. Accepted for publication Aug 20, 2021.

doi: $10.21037 /$ jtd-21-1220

View this article at: https://dx.doi.org/10.21037/jtd-21-1220

International epidemiological studies demonstrated an increased age-adjusted lung-cancer incidence rates in females in recent decades, in contrast to a trend of decrease in the males $(1,2)$. Although an increased prevalence of smoking or environmental exposure to tobacco in females may be accountable, the unparallel growth spurt of female lung-cancer cases, especially in the premenopausal population, suggested an etiological involvement of sex hormones (3). Despite the controversy, emerging evidence at both clinical and molecular levels had shown important interaction between tobacco carcinogens and endogenous and exogenous sex steroids (4-6). Sex hormone-regulated enzyme activity in carcinogen metabolism was proposed as one of the potential explanations (5), and further study suggested the sex-specific expression of nuclear and cytoplasmic estrogen receptors in lung tissue also played a pivotal role (7). The potential estrogen-related increased susceptibility to carcinogenesis or tumor progression raises concern to pregnant women, whose serum estrogens and progesterone surges to a very high level after the first trimester of pregnancy.

Recently, a retrospective study with literature pooled analysis examined the clinical features and timing of intervention in 77 patients with pregnancy-associated lung cancers (8). They analyzed the overall survival (OS) in patients of different molecular features, timing of diagnosis and treatment. They found no significant different survival outcome between patients treated during pregnancy or after delivery $(\mathrm{P}=0.173)$. However, patients with activating mutations such as anaplastic lymphoma kinase (ALK) gene rearrangement and epidermal growth factor receptor (EGFR) achieved a significantly better OS than those with wild-type $(\mathrm{P}<0.001)$. They therefore endorsed the use of targeted therapy for this special population. Although the treatment dilemma was put forward and discussed in this study, no conclusive result and recommendation can be reached due to its limited sample size. We appreciate the authors' efforts in collecting this comprehensive case series of pregnancy-associated lung cancers. However, after a careful reading of this study, we believe that the data presented could be more informative beyond treatment timing or regimens.

First and the most interestingly, almost all patients had their lung cancer diagnosed after the first trimester of pregnancy (9/9 in Guangdong Lung Cancer Institute and 54/64 in literature reports, excluding missing data or diagnosed after death), in parallel to the increased serum level of sex hormones. Moreover, the median time intervals from symptom onset to hospital were 1.5 and 2 months in these two different groups of patients, respectively (8). That is to say, a rapid progression of lung cancer, if previously existed, to an advanced symptomatic stage, might be in close relationship with the pregnancy-driven surging of hormones (Figure 1). To elucidate this, it is necessary for

^ ORCID: Weitao Zhuang, 0000-0002-8679-4109; Guibin Qiao, 0000-0001-9200-9317. 


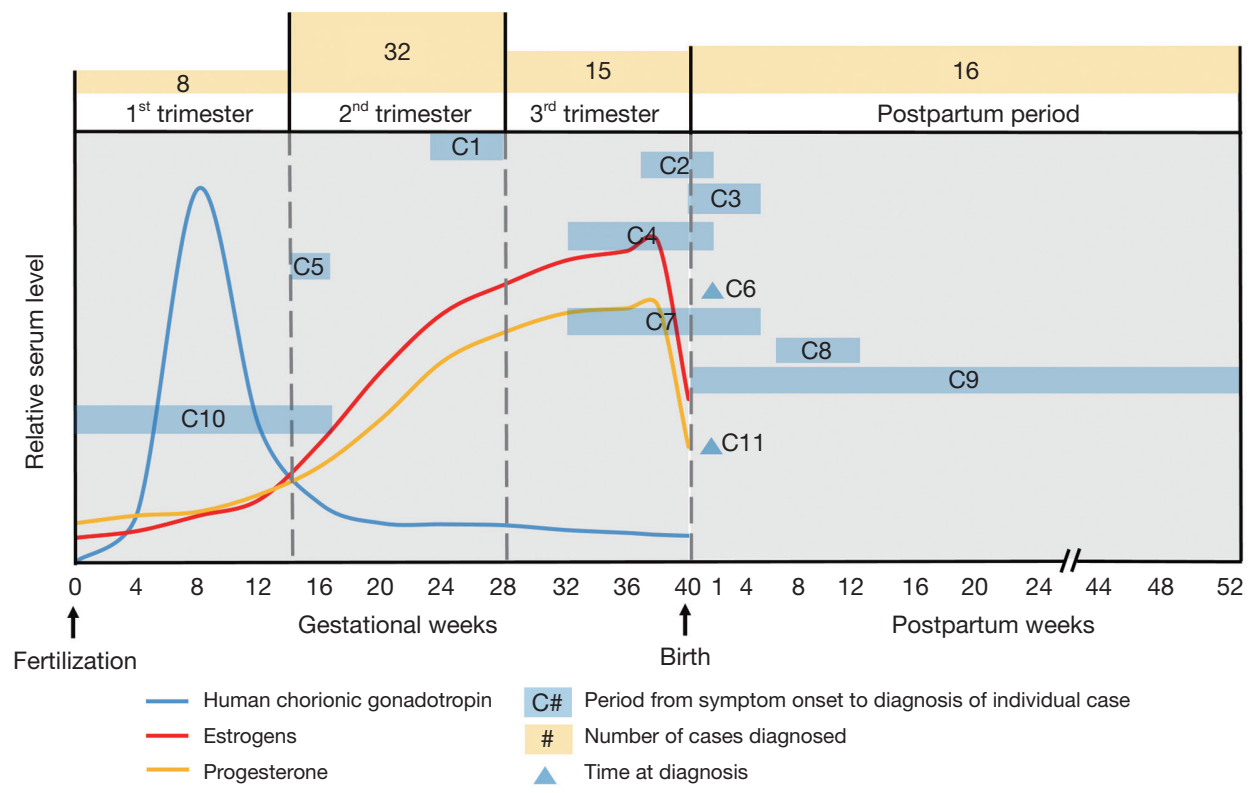

Figure 1 Timing of symptom onset and diagnosis of pregnancy-associated lung cancers and their relative relationship to serum change of female sex hormone. Source data extracted from (8).

the authors to provide the pre-gestational chest computed tomography (CT) or chest X-ray. Given that most patients (71/77) were diagnosed with stage III to IV lung cancers in this study, the unfavorable outcome forces us to consider the involvement of chest CT scan in antenatal examination. To go further, surgical resection of high-risk indeterminate ground glass opacity or part-solid nodules before getting pregnant should be considered to avoid the surveillance or treatment dilemma during pregnancy. Although more evidences on the underlying molecular mechanism of sex hormone to carcinogenesis are needed to resolve this clinical challenge, the possibility of cancer progression and metastasis should be opened for discussion in clinics of preconception counseling, and the involvement of an experienced thoracic surgeon is necessary to achieve shared decision-making.

Secondly, Yang reported most patients presented with symptoms of cough, dyspnea, and chest/back pain (8), which were resulted from the local compression or invasion of tumors. Therefore, these patients were assumed to be at an advanced $T$ stage, suggesting a rapid growth in size during pregnancy. We request the authors to provide the TNM staging details or tumor sizes of these patients, along with the available pre-gestational CT results, which will offer an interesting perspective in this topic of controversy.

Thirdly, Yang reported a median OS of 1 month in
6 patients with no treatment to lung cancer, under the comparison among groups of different treatment timing (8). This result might be misleading unless specific reasons of death or cancer-specific survival were provided. This group of patients may die of pregnancy-related complications before receiving any anti-cancer treatments.

Last but not the least, we suggest the authors to further compare the outcomes between groups with or without termination of pregnancy. This is a very important clinical question as well as a tough choice for the patients and their families. However, there is currently a scarcity of data on this clinical setting. Once the relationship between sex hormone and cancer progression is established, whether the termination of pregnancy can decelerate the progression of cancer or provide better outcome should be investigated. Different patient-centered strategies according to clinical stages are also needed for balancing the benefits to the mother and fetus.

As more and more young females are diagnosed with lung cancer, the pregnancy-associated lung cancer is becoming an important research topic in the near future. The mitogenic or carcinogenic effect of female sex hormone is well known in the female reproductive system, while little is known in the cancers of respiratory system. To cope with this clinical and scientific challenge, substantial works are needed to elucidate the underlying molecular pathways, and 
to formulate standard procedures of prevention, diagnosis, monitoring and treatment.

\section{Acknowledgments}

Funding: This article was supported by grants from 2020 Guangdong Provincial Special Project for Popularization of Science and Technology Innovation (grant number: 2020A1414070007).

\section{Footnote}

Provenance and Peer Review: This article was a standard submission to the journal. The article did not undergo external peer review.

Conflicts of Interest: Both authors have completed the ICMJE uniform disclosure form (available at https://dx.doi. org/10.21037/jtd-21-1220). The authors have no conflicts of interest to declare.

Etbical Statement: The authors are accountable for all aspects of the work in ensuring that questions related to the accuracy or integrity of any part of the work are appropriately investigated and resolved.

Open Access Statement: This is an Open Access article distributed in accordance with the Creative Commons Attribution-NonCommercial-NoDerivs 4.0 International License (CC BY-NC-ND 4.0), which permits the noncommercial replication and distribution of the article with the strict proviso that no changes or edits are made and the original work is properly cited (including links to both the formal publication through the relevant DOI and the license). See: https://creativecommons.org/licenses/by-nc-nd/4.0/.

\section{References}

1. Cheng TY, Cramb SM, Baade PD, et al. The International Epidemiology of Lung Cancer: Latest Trends, Disparities, and Tumor Characteristics. J Thorac Oncol 2016;11:1653-71.

2. Siegfried JM. Women and lung cancer: does oestrogen play a role? Lancet Oncol 2001;2:506-13.

3. Stapelfeld C, Dammann C, Maser E. Sex-specificity in lung cancer risk. Int J Cancer 2020;146:2376-82.

4. Slatore CG, Chien JW, Au DH, et al. Lung cancer and hormone replacement therapy: association in the vitamins and lifestyle study. J Clin Oncol 2010;28:1540-6.

5. Stapelfeld C, Neumann KT, Maser E. Different inhibitory potential of sex hormones on NNK detoxification in vitro: A possible explanation for gender-specific lung cancer risk. Cancer Lett 2017;405:120-6.

6. Zang EA, Wynder EL. Differences in lung cancer risk between men and women: examination of the evidence. J Natl Cancer Inst 1996;88:183-92.

7. Cheng TD, Darke AK, Redman MW, et al. Smoking, Sex, and Non-Small Cell Lung Cancer: Steroid Hormone Receptors in Tumor Tissue (S0424). J Natl Cancer Inst 2018;110:734-42.

8. Yang L, He YT, Kang J, et al. Clinical features and intervention timing in patients with pregnancy-associated non-small-cell lung cancer. J Thorac Dis 2021;13:4125-36.
Cite this article as: Zhuang W, Qiao G. Pregnancyassociated lung cancer: a clinical and scientific challenge more than treatment dilemma. J Thorac Dis 2021;13(9):5572-5574. doi: $10.21037 /$ jtd-21-1220 